\title{
The Influence of Older Classmates on Adolescent Sexual Behavior in Cape Town, South Africa
}

\author{
David Lam, Letícia J. Marteleto, and Vimal Ranchhod
}

\begin{abstract}
This study examines the influence of exposure to older within-grade peers on sexual behavior among students in urban South Africa. Data are drawn from the Cape Area Panel Study, a longitudinal survey of young people conducted in metropolitan Cape Town from 2002 to 2006. The combination of early sexual debut, high rates of school enrollment into the late teens, and grade repetition create an environment in which young people who progress through school ahead of many in their cohort interact with classmates who may be several years older. We construct a measure of cumulative exposure to classmates who are at least two years older and show that such exposure is statistically significantly associated with early sexual initiation among adolescent girls. This exposure also increases the age difference between these girls and their first sexual partner, and helps explain a significant proportion of the earlier sexual debut of African girls, compared with colored and white girls in Cape Town. (STUDIES In FAmily Planning 2013; 44[2]: 147-167)
\end{abstract}

I

n urban South Africa, school enrollment rates are high through at least age 18. Significant proportions of black South Africans (referred to as "Africans") remain enrolled in secondary school beyond age 20, a result of high rates of grade repetition and high payoffs for completing twelfth grade (Anderson, Case, and Lam 2001; Lam, Ardington, and Leibbrandt 2011). Second, most African adolescents become sexually active by age 18 . As shown by Dinkelman and colleagues (2007), 72 percent of 17-18 year-old African young women in Cape Town reported having had sex in 2005. The combination of these two patterns means that most young people in Cape Town become sexually active while still in school.

Research from a number of other African countries has contended that school enrollment has the "protective effect" of delaying sexual debut (Lloyd 2005 and 2007; Biddlecom et al. 2008; Darabi et al. 2008; Clark and Mathur 2012). These studies indicate that schools have the capacity to enhance success in many transitions to adulthood, mainly through the acquisition of knowledge and skills, but they also note that schools can be a place of conflict and social-

David Lam is Professor, Department of Economics, University of Michigan, Ann Arbor, MI. Letícia J.

Marteleto is Assistant Professor, Department of Sociology, University of Texas at Austin, 305 E. 23rd Street, G1800, Austin, TX 78712. E-mail: marteleto@prc.utexas.edu. Vimal Ranchhod is Research Associate, Department of Economics, University of Cape Town, Rondebosch, South Africa. 
ization to undesirable behaviors. Teachers, principals, and peers each play important roles in young people's schooling experiences and in how these experiences will relate to subsequent transitions to adulthood. Belonging to a positive peer group likely leads to a positive effect on adolescents' schooling outcomes. At the same time, being exposed to an older and therefore more sexually active peer group might encourage adolescents to become sexually active.

Because most adolescents in urban South Africa become sexually active before they leave school, the "protective effect" of schools may not extend to protection from risky sex. One of the intriguing results found in previous analyses of sexual debut in urban South Africa (using the same data as in this study) was a positive effect of baseline grade attainment on sexual debut in the subsequent four years, controlling for baseline age (Dinkelman, Lam, and Leibbrandt 2007 and 2008; Marteleto, Lam, and Ranchhod 2008). Estimating probit regressions of a number of individual and household characteristics on sexual debut, Marteleto and colleagues (2008) found that the number of grades completed by 2002 had a significant positive effect on sexual debut between 2002 and 2005 for both boys/young men and girls/young women who were aged 14-16 in 2002. These positive effects of schooling on sexual debut, controlling for age, are surprising because we might expect that young people who are ahead of their age group in school would be less likely to become sexually active. The estimates imply that a girl aged 14-16 who had completed one extra grade in 2002 , given her age, was 6.6 percentage points more likely to sexually debut by 2005 . The effect for young men was slightly greater at 8 percentage points.

One possible interpretation of this result is that young people who are ahead of many in their cohort in school interact with an older and more sexually active group of young men and women. Because of the high rates of grade repetition in South Africa, students in any given grade in secondary school span a wide range of ages, especially in predominantly African schools. Adolescents could be influenced by the behavior of older same-sex peers and by interactions with older opposite-sex peers. We hypothesize that the effects on sexual initiation of grades completed is a consequence of two offsetting mechanisms. The first is that students who do better in school may be less likely to become sexually active. The second is that the influence of older peers is toward encouraging sexual debut. We attempt to disentangle these two effects in our models by using a literacy and numeracy proficiency measure in addition to a constructed measure of exposure to older peers.

This study explores these possible peer effects in greater detail in the South African context. Our analysis is similar in nature to recent research in the United States that tries to identify "contagion" effects of interacting with older peers. A recent article by Argys and Rees (2008), for example, uses variation in the mandated age at which children begin school across the United States as an exogenous source of variation in exposure to older classmates during the teenage years. Another study used the variation in whether ninth graders are grouped with tenth- to twelfth-grade students or with seventh- to eighth-grade students (Eisenberg 2004).

A significant body of research has been conducted in the US on the effects of peers on the behavior and life decisions of students at various levels. Exploiting the random assignment of college roommates, Sacerdote (2001) found evidence of peer effects among roommates on academic outcomes and decisions to join social groups. Analyzing tenth-grade classmates in the National Education Longitudinal Study (NELS) of 1988, Gaviria and Raphael (2001) found evidence of peer effects at the school level on substance use, church attendance, and dropping out of high school. Using US data from the National Longitudinal Survey of Adolescent 
Health, Sieving and colleagues (2006) found that a significant positive relationship existed between the proportion of a young person's friends who were sexually active in Wave 1 and the probability of sexual debut between Waves 1 and 2 .

Our analysis takes advantage of the high variance in age-for-grade distributions in Cape Town, especially in predominantly nonwhite schools. An important feature of Cape Town is the continuing large socioeconomic disparities and the high degree of spatial segregation across the three major racial groups (referred to as "population groups" in South Africa): African, colored, and white. (The Cape Town population in the 2001 census was 32 percent African, 48 percent colored, and 19 percent white). These three groups were subject to differing treatment under apartheid. Whites had advantages in most areas, including significantly greater expenditures on schooling, privileged access to the labor market, unrestricted residential mobility, and better access to social services. Africans had the least access to services and the most restrictions on work and migration, with a large gap in expenditures on schooling. The colored population, which is heavily concentrated in the Western Cape (including Cape Town), occupied an intermediate status under apartheid, with greater expenditures on schooling, fewer restrictions on residential mobility, and better access to jobs than Africans. ${ }^{1}$ Using retrospective schooling histories, we estimate the exposure of respondents to older classmates beginning at age 12 and examine whether this exposure is associated with an increased probability of sexual debut.

\section{DATA AND METHODS}

We use data from Waves 1-4 of the Cape Area Panel Study (CAPS), a longitudinal survey of adolescents and young adults conducted from 2002-06 in metropolitan Cape Town. Details regarding the design of CAPS are provided in Lam and colleagues (2008). ${ }^{2}$ Wave 1, conducted in 2002, included a household questionnaire, which collected information about the household and all household residents from a knowledgeable adult household member, and a young adult questionnaire that was administered to up to three individuals aged 14-22. The young adult questionnaire collected data concerning a wide range of topics, including sexual behavior, schooling, and employment. The young adult questionnaire also included a literacy and numeracy evaluation (LNE) and a life history calendar that provides retrospective information regarding living arrangements, schooling, and pregnancy. The LNE was a self-administered written test taken after completion of the young adult questionnaire. The test consisted of 45 questions and took about 20 minutes to complete. Respondents could choose to take the test in English or Afrikaans. No version was available in Xhosa, the native language of most African respondents.

CAPS was designed using a two-stage probability sample of households, with an oversampling of African and white households to obtain large enough samples to make meaningful comparisons across groups. The baseline wave of CAPS surveyed 4,751 young adults living in 3,304 households. As in most South African household surveys, response rates were high in

1 The colored population, which was about 9 percent of the country in the 2001 census, includes descendants from indigenous Khoisans and the Dutch slaves from Malaysia and other areas. This population is predominantly Afrikaans speaking, and about 20 percent identified as Muslim in the Cape Area Panel Study. Under apartheid, the colored population (concentrated in Cape Town) was a separate racial classification from the Indian population (concentrated in Durban) and from the roughly 80 percent of the population classified as African.

2 The Cape Area Panel Study is a collaborative project of the University of Michigan and the University of Cape Town, funded by the US National Institutes of Health. Additional details and technical documentation are available at $<$ www.caps.uct.ac.za $>$. 
African and colored areas, and low in white areas. Household response rates were 89 percent in African areas, 83 percent in colored areas, and 46 percent in white areas. ${ }^{3}$ Young adult response rates, conditional on household participation, were high, even in white areas. Given household participation, the response rate for young adults was 93 percent in African areas, 88 percent in colored areas, and 86 percent in white areas (Lam et al. 2008). We use the household questionnaires for information regarding parents' characteristics, living arrangements, household income, and household shocks. We use the young adult individual questionnaires for information concerning education, sexual activity, and literacy/numeracy scores.

Table 1 shows the sample size by racial group and provides information regarding attrition between waves. We show information for the full sample aged 14-22 in 2002 and for the subset aged 14-17 in 2002, the sample we use for our regressions. As intended in our sample design, the original Wave 1 sample included roughly equal numbers of African and colored respondents. The weighted percent column shows that when sample weights are used to adjust for the sample design and differential response rates, the weighted sample is 28 percent African, 53 percent colored, and 19 percent white, proportions that are similar to those found for the same age group in Cape Town in the 2001 South African census (Lam et al. 2008).

The young adult questionnaire within CAPS Wave 3, collected in 2005, provides most of the longitudinal information used in this study. Of the 4,751 original respondents, 3,531 were successfully interviewed in Wave 3 (see Table 1). In Wave 4, collected in 2006, we located almost 400 additional respondents who were missed in 2005. Because we collect retrospective data regarding variables such as schooling and sexual activity since the last interview, we can use Wave 4 data to fill in information concerning 2005 outcomes for respondents who were in Wave 4 but not in Wave 3. The effective sample for 2005 outcomes, then, is 3,916, implying an 18 percent attrition rate between 2002 and 2005 .

As shown in Table 1, attrition differs significantly by race. The African attrition rate is 20 percent, with proxy reports indicating that most attrition is a result of migration back to the rural Eastern Cape province, the main sending region among Africans living in Cape Town.

TABLE 1 Sample size, percentage of sample, and attrition between survey waves, by race, Cape Town, South Africa, 2002-06

\begin{tabular}{|c|c|c|c|c|c|c|}
\hline Racial group & $\begin{array}{r}\text { Interviewed } \\
\text { in Wave } 1\end{array}$ & $\begin{array}{r}\text { Unweighted } \\
\text { percent }\end{array}$ & $\begin{array}{r}\text { Weighted } \\
\text { percent }\end{array}$ & $\begin{array}{r}\text { Interviewed } \\
\text { in Wave } 3\end{array}$ & $\begin{array}{r}\text { Interviewed } \\
\text { in Wave } 3 \\
\text { or } 4\end{array}$ & $\begin{array}{r}\text { Attrition from } \\
\text { Wave } 1 \text { to } \\
\text { Wave } 3 \text { or } 4 \\
\text { (percent) }\end{array}$ \\
\hline \multicolumn{7}{|c|}{ Full sample aged $14-22$ in 2002} \\
\hline African & $(2,151)$ & 45.3 & 28.2 & $(1,515)$ & $(1,724)$ & 19.9 \\
\hline Colored & $(2,005)$ & 42.2 & 53.2 & $(1,679)$ & $(1,801)$ & 10.2 \\
\hline White & $(595)$ & 12.5 & 18.6 & $(337)$ & $(391)$ & 34.3 \\
\hline Total & $(4,751)$ & 100.0 & 100.0 & $(3,531)$ & $(3,916)$ & 17.6 \\
\hline \multicolumn{7}{|c|}{ Sample aged 14-17 in 2002} \\
\hline African & $(902)$ & 41.09 & 25.7 & $(696)$ & $(772)$ & 14.4 \\
\hline Colored & $(999)$ & 45.51 & 55.3 & $(881)$ & $(935)$ & 6.4 \\
\hline White & $(294)$ & 13.39 & 19.0 & $(205)$ & $(228)$ & 22.4 \\
\hline Total & $(2,195)$ & 100.0 & 100.0 & $(1,782)$ & $(1,935)$ & 11.8 \\
\hline
\end{tabular}

SOURCE: Young adult questionnaire within Cape Area Panel Study, Waves 1-4.

3 As discussed by Lam and colleagues (2008), household response rates were lower in high-income areas. Sample weights adjust for differential response rates within sample clusters, which partially accounts for differential response rates that are correlated with sample cluster characteristics such as income. In practice, results are little affected by sample weights when race dummies are included in regressions. 
The colored population has strong roots in Cape Town, a factor in its lower (10 percent) attrition rate. The 34 percent attrition rate for whites includes both migration out of Cape Town (including out of South Africa) and a significant number of refusals to participate in the survey. The bottom panel of Table 1 shows the sample size and attrition rates for the sample that was aged 14-17 in 2002, the group we use in our regressions. Attrition for this group (12 percent) is considerably lower than for the full sample, a reflection of the positive relationship between age and attrition.

We have also analyzed attrition using probit regressions of 2002-2005 attrition on baseline characteristics (not shown). In addition to being correlated with age and race, attrition is negatively correlated with baseline grade attainment and school enrollment. Attrition is not significantly correlated with whether the respondent was sexually active at baseline, once we control for variables such as age, race, household income, and parental education - all of which we control for in our regressions. As a robustness test for the regressions reported below, we have estimated the regressions using inverse probability weights following the approach of Fitzgerald and colleagues (1998). The results are virtually identical in the weighted regressions, giving us confidence that sample attrition does not have a major impact on our results. ${ }^{4}$

\section{Variables}

Our key outcome variables are self-reports of sexual debut and of age of first sexual partner. For sexual debut we use two questions, the first concerning whether the respondent ever had sex and the second concerning the age at which respondent first had sex. For most respondents, we examine whether they report having had sex at Wave 3 (2005), conditional on not having had sex at Wave 1 (2002). For respondents captured in Wave 4 (2006) but not in Wave 3, we use their report of age at first sex to determine whether they had sex by 2005. We also use information regarding the age of the first sexual partner, a question that appears in Waves 3 and 4.

Our key independent variable is exposure to older peers. The CAPS data do not allow us to observe the actual distribution of ages in the schools attended by respondents. We can use patterns of grade-for-age distribution, however, to estimate the age distribution of students in a given grade. We take advantage of CAPS' complete schooling history for all respondents. This allows us to generate a race-specific age-for-grade distribution for each grade, pooling the retrospective histories for all respondents. We use these to generate an estimate of the age distribution of students that each respondent experienced at every age since starting school.

Note that to do this we require that grade completion in 2002 is not perfectly correlated with our exposure measure. In a regime in which all students progress one grade per year, both highest grade completed and our exposure measure might have some variation for students of a given age because of differences in the age at which students began school. ${ }^{5}$ In our case, we have considerable additional variation because of the high levels of grade repetition in South African schools.

Our measure of exposure to older peers is constructed as follows. We use the retrospective schooling histories to construct age-for-grade distributions for every grade for each of the three

4 Attrition in the relevant age group is only 12 percent, attrition is uncorrelated with sexual activity at baseline, and our results are unaffected by adjustments for attrition.

5 This is the source of variation exploited by Argys and Rees (2008), who use differences in the mandated age at starting school across the United States as an instrument for exposure to older classmates. 
racial groups. For each respondent, we look at the grade they were attending at age 12 using the retrospective schooling history. We take the race-specific age-for-grade distribution for that grade and calculate the percentage of students who would have been at least two years older than the respondent. For example, if an African respondent were in eighth grade at age 12, we take the percentage of eighth graders who are 14 and older in the typical African age-for-grade distribution (67 percent) and assign that value as the percentage who were at least two years older than the respondent when she was 12 . We make the same calculation at each age up to the age of the respondent in Wave 1, using only respondents who were aged 14-17. Respondents who are not enrolled in school are given a zero for the exposure measure for that age. ${ }^{6}$

We sum these age-specific exposure measures across years from age 12 through their Wave 1 age. For example, if the student were in eighth grade at age 12, repeated eighth grade at age 13 , advanced to ninth grade at age 14 , and was age 14 in Wave 1 , she or he would have a total exposure of $0.67+0.42+0.43=1.52$. All African respondents with the same schooling history will be assigned the same value. This can be thought of as a measure of person-years of exposure from age 12 to classmates who were at least two years older. For a 14-year-old in 2002, this has a theoretical maximum of 3, implying that 100 percent of students were at least two years older than the respondent in every grade since age 12. For 14-year-old Africans in Wave 1 , the mean of our exposure measure is 0.62 , the standard deviation is 0.44 , with a range from 0 to 1.98 . The distribution for 14 -year-old whites is very different, with a mean of only 0.07 , a standard deviation of 0.13 , and a range from 0 to 0.93 .

We use this exposure measure in regressions to see whether it predicts sexual debut between 2002 and 2005. The grade variable and the exposure variable will move together as students progress, however, making it difficult to estimate separate effects of the two variables. In our case, we take advantage of the high levels of grade repetition, especially in African and colored schools. This means that two 16-year-olds in seventh grade in 2002 may have had very different grade trajectories since age 12. Although the correlation between our exposure measure and highest grade completed ranges between 0.85 and 0.91 for Africans for each age from 14-17, we see that we are able to estimate a statistically significant effect of the exposure measure.

A key assumption of our measure is that African students face the grade-for-age distribution displayed by all African students. In other words, we assume that the African age-forgrade distribution is identical in all African schools and that Africans only attend African schools. Analogous assumptions are made for colored and white students. Although these are strong assumptions, several reasons lead us to think that they are a reasonable approximation of reality. First, schools in Cape Town, like schools across South Africa, continue to be highly segregated. Lam and colleagues (2011) show that only 11 percent of Africans in eighth or ninth grade in 2002 attended historically colored schools and only 3 percent attended historically white schools. Although all African schools are not identical, the differences between African and white schools in all dimensions, including age-for-grade distributions, are vastly greater than differences within the group of African (or white) schools.

Another important consideration for our analysis is Lam and colleagues' (2011) finding that grade repetition is poorly linked to actual learning, especially for Africans. They find

6 The assumption that no exposure to older peers takes place when young people are out of school is fairly unimportant because 96 percent of the sample in our regressions was continuously enrolled since age 12 . To the extent that our measure misses peer exposure when young people are out of school, we will be biased against finding an effect of our exposure measure. 
that there is a stochastic component to grade advancement that is uncorrelated with learning, suggesting that some component of our exposure measure may be unrelated to school performance. Because we will also be including grade attainment and a measure of literacy and numeracy in Wave 1, we will be able to isolate the effect of older peers from whatever association may exist between school performance and sexual debut.

\section{Results Supporting Inclusion of Measure of Exposure to Older Classmates}

To have potential for contagion effects from exposure to older classmates, we need to see two patterns in the data. First, we need to see a fairly steep age gradient in the behavior for which we expect there to be contagion effects. Students need to be exposed to significantly different behavior when they interact with, for example, 17-year-old classmates than when they interact with 15-year-old classmates. Second, variation needs to be present in the degree to which students are exposed to older peers, with some students experiencing significant exposure.

We present evidence regarding the age gradient in the outcomes we are studying and the age-for-grade distributions in African, colored, and white schools. We also define the measure of exposure to older peers that will be used in our regression analysis. We begin by documenting the age profiles concerning sexual debut. Figure 1 shows age profiles by race and sex for sexual initiation from age 14-22 as reported in CAPS Wave 1. As shown in the left panel, the age gradient for sexual debut is steep for all three racial groupings and both sexes, but particularly among young Africans. For example, the proportion of African girls/young women who reported having had sex rose from less than 5 percent at age 14 to 32 percent at age 16 and to 68 percent at age 18. A 16-year-old whose classmates are aged 14-16 would have a different level of exposure to sexually active classmates than a 16-year-old whose classmates are aged 16-18. As shown in Figure 1, colored and white young people initiate sexual activity somewhat later than do Africans, although the age gradient is nevertheless steep.

A useful summary measure of the slope of the age gradients in Figure 1 is a simple ordinary least squares regression of the binary outcome on age. Table 2 shows this age coefficient for

FIGURE 1 Percentage of respondents who had sex before Wave 1, CAPS respondents aged 14-22, Cape Town, South Africa, 2002

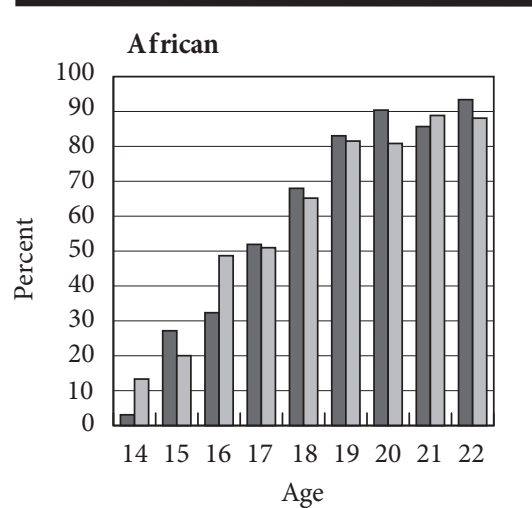

Age
Colored

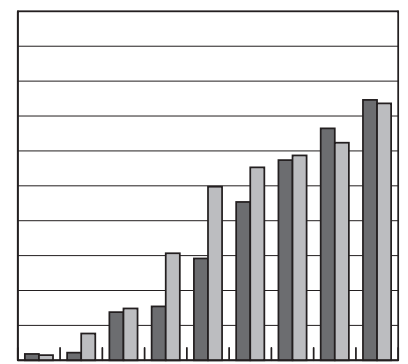

$\begin{array}{lllllllll}14 & 15 & 16 & 17 & 18 & 19 & 20 & 21 & 22\end{array}$ Age
White

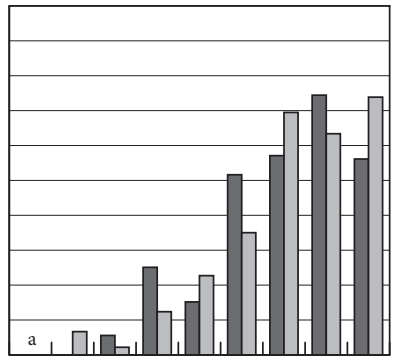

$\begin{array}{lllllllll}14 & 15 & 16 & 17 & 18 & 19 & 20 & 21 & 22\end{array}$ Age

\footnotetext{
${ }^{\mathrm{a}}$ The percentages for white 14-year-old boys and girls and white 15-year-old girls are all zero.
} 
TABLE 2 Results of ordinary least squares regressions of sexual debut on age, CAPS respondents aged 14-20 in Wave 1, Cape Town, South Africa, 2002

\begin{tabular}{lcrrr}
\hline Group & Constant & $\begin{array}{c}\text { Age } \\
\text { coefficient }\end{array}$ & Observations & $\mathbf{R}^{2}$ \\
\hline African girls/young women & $-1.962^{* *}$ & $0.145^{* *}$ & $(970)$ & 0.31 \\
African boys/young men & $-1.551^{* *}$ & $0.122^{* *}$ & $(726)$ & 0.24 \\
Colored girls/young women & $-1.387^{* *}$ & $0.095^{* *}$ & $(862)$ & 0.19 \\
Colored boys/young men & $-1.523^{* *}$ & $0.108^{* *}$ & $(779)$ & 0.21 \\
White girls/young women & $-1.445^{* *}$ & $0.098^{* *}$ & $(236)$ & 0.22 \\
White boys/young men & $-1.502^{* *}$ & $0.100^{* *}$ & $(239)$ & 0.23 \\
\hline
\end{tabular}

**Significant at $\mathrm{p}<0.01$.

NOTE: Having had sex prior to Wave 1 is the dependent variable.

each of the six sex/race combinations. We use the sample aged 14-20 because this age range is most relevant for our analysis of peer exposure during secondary school. As seen in Table 2, among Africans the probability of sexual debut rises by 12 and almost 15 percentage points per year of age for African boys/young men and girls/young women, respectively, and about 10 percentage points per year of age for the other groups.

An important component of our argument is that some students are exposed to classmates spanning a wide age range. We present evidence on the age-for-grade and grade-for-age distributions for students in the age range where contagion effects may be important. Figure 2 illustrates the distribution of respondents by current grade, according to age $(14,15$, and 16) in Wave $1 .^{7}$ Large racial differences in grade-for-age are immediately apparent. Among white 14-year-olds, 57 percent are in eighth grade, 97 percent are between seventh and ninth grade, and none are below seventh grade. Among African 14-year-olds, only 28 percent are in eighth grade, 53 percent are between seventh and ninth grade, and 18 percent are below seventh grade. Similar patterns are observed at age 15 and 16, with African students having much greater dispersion in grade-for-age than white or colored students.

Figure 3 looks at this a different way, showing the age distribution of students in ninth, tenth, and eleventh grade. Naturally, the grade-for-age dispersion in Figure 2 is reflected in the age-for-grade distributions in Figure 3. Among white tenth graders, for example, 46 percent are aged 16, 95 percent are 15-17 (which might be considered the normative age range for tenth grade), and less than 2 percent are older than 17. Among African tenth graders, only 20 percent are aged 16, 53 percent are 15-17, and 44 percent are older than 17. If the African grade-forage distributions are typical of all African schools in Cape Town, an African 15-year-old girl in tenth grade would be at least two years younger than 62 percent of her classmates and at least three years younger than 44 percent of her classmates. In contrast, a white 15 -year-old girl in tenth grade would be at least two years younger than only 5 percent of her classmates and at least three years younger than only 1 percent of her classmates, assuming she were in a school with a grade-for-age distribution represented by the white students in CAPS. The potential for contagion effects from interacting with older classmates is clearly great for African students who are not behind in school.

Table 3 shows the proportion of students who are two or more years older and three or more years older than the normative age for each grade among students in grades 9-11. (We

7 Age-for-grade and grade-for-age distributions depend on the time of the school year at which the measures are calculated. We calculated each respondent's age and grade as of 1 July 2002 to construct Figures 2 and 3. This date is roughly the middle of the South African school year. 
FIGURE 2 Grade distribution by age, according to race, CAPS Wave 1, Cape Town, South Africa, 2002
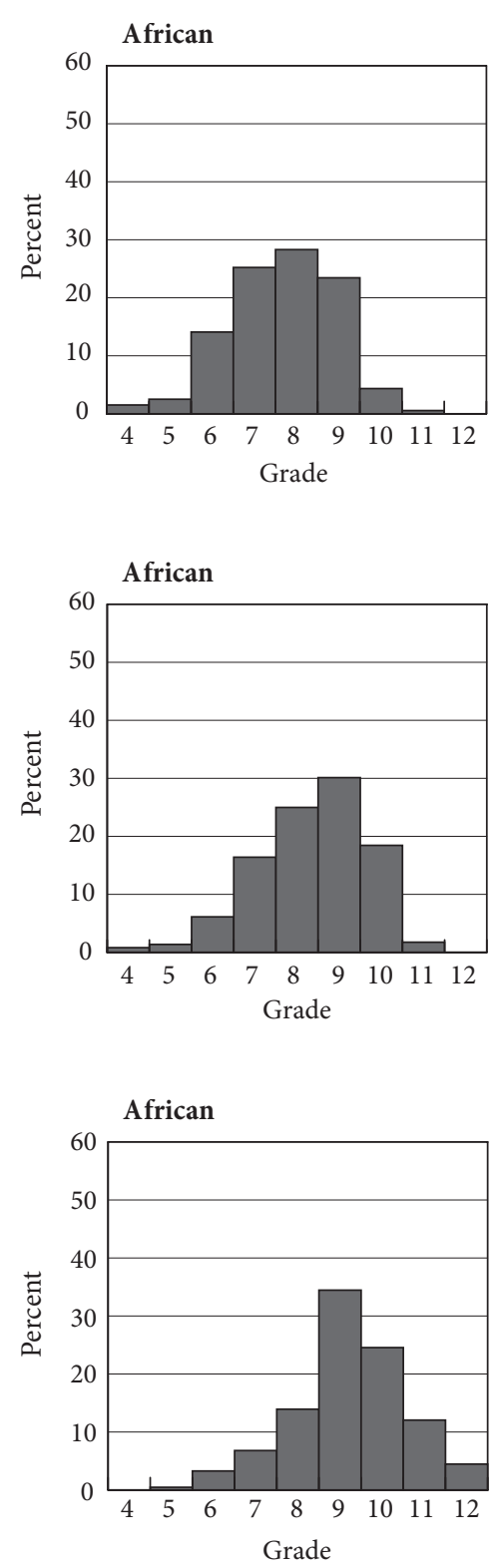

Age 14

Colored

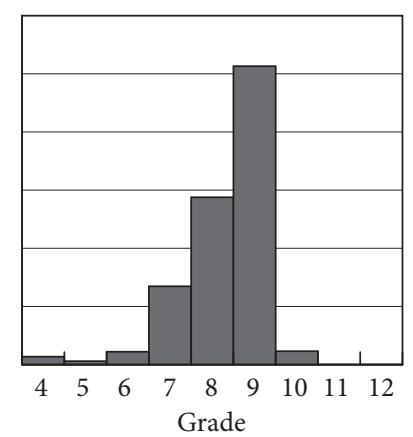

Age 15

Colored

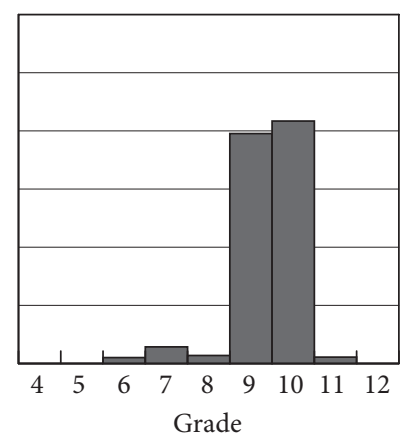

Age 16

Colored

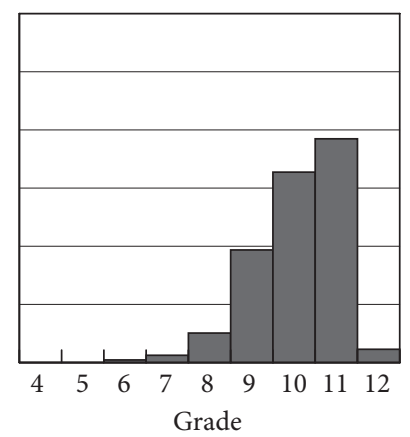

White

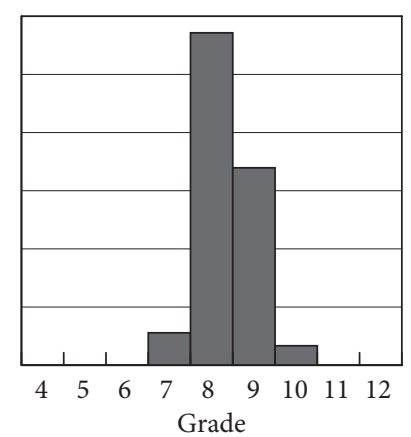

White

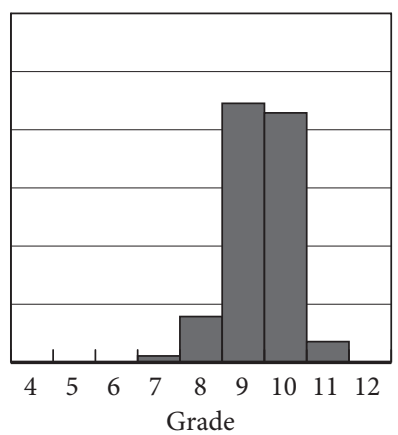

White

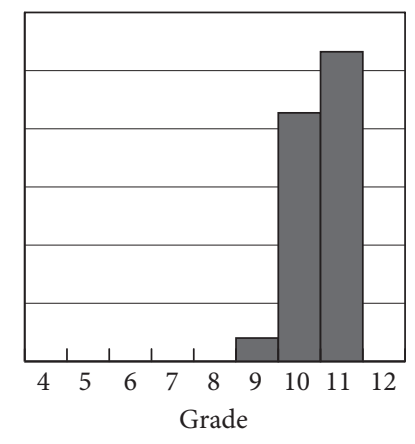

NOTE: Age as of 1 July 2002.

assume that the normative ages are 15 for ninth grade, 16 for tenth grade, and 17 for eleventh grade.) Among African boys/young men in grades 9-11, 57 percent are at least two years older than the normative age for their grade. This compares with 43 percent for African girls/young women. Although grade repetition is common for both boys/young men and girls/young women in predominantly African schools, repetition rates are considerably greater for males (Lam, Ardington, and Leibbrandt 2011). Colored respondents are considerably less likely than 
FIGURE 3 Age distribution by grade, according to race, CAPS Wave 1, Cape Town,

South Africa, 2002

Grade 9

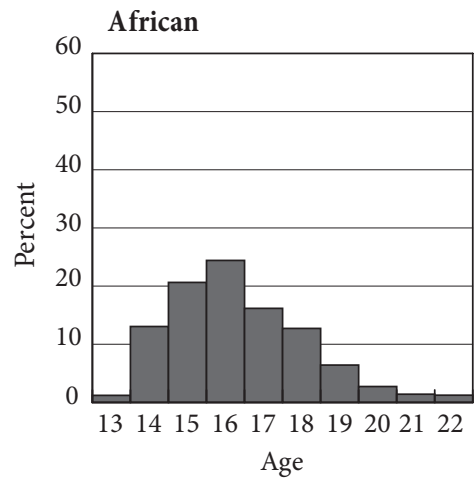

Colored

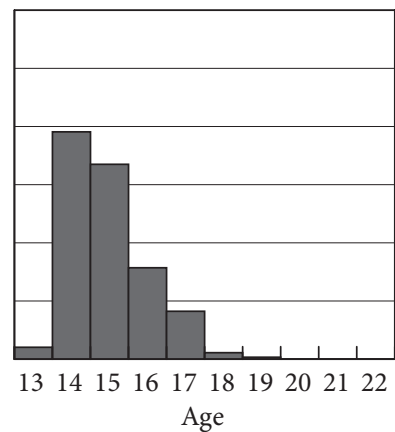

Grade 10

Colored

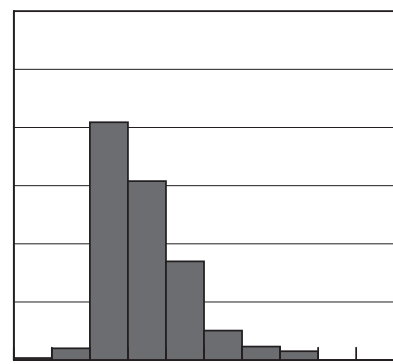

$1314151617 \quad 1819202122$ Age

Grade 11

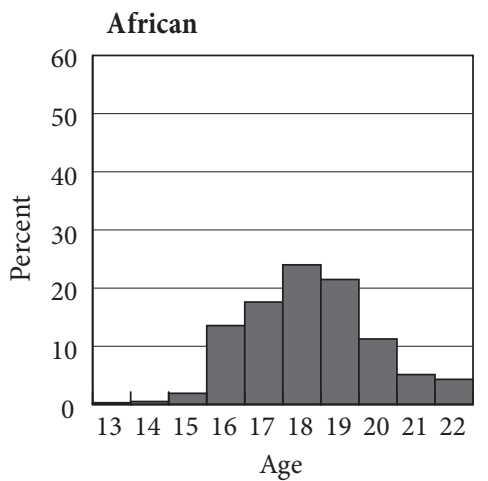

White

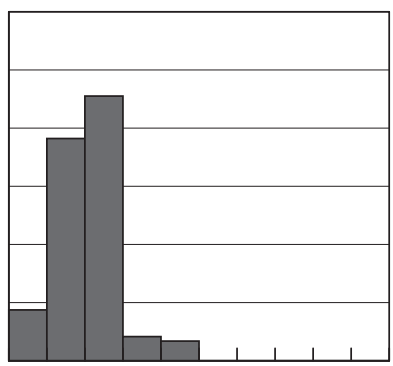

$13 \quad 14 \quad 151617 \quad 1819202122$ Age

White

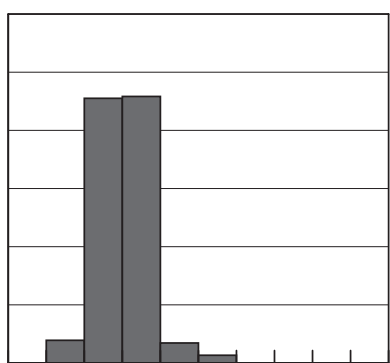

$\begin{array}{llllllllll}13 & 14 & 15 & 16 & 17 & 18 & 19 & 20 & 21 & 22\end{array}$ Age

White

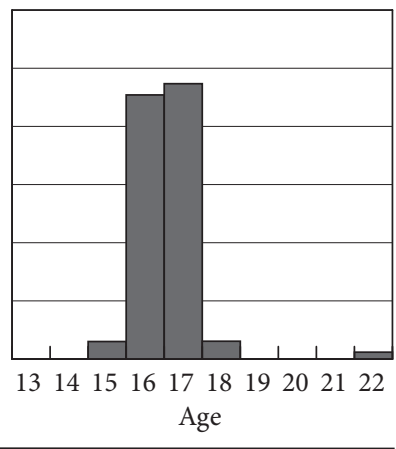

NOTE: Age as of 1 July 2002.

Africans to be two or more years older than the normative age for grade. This reflects both lower rates of grade repetition and the fact that colored students are more likely than Africans to drop out of school when they fail a grade (Lam, Ardington, and Leibbrandt 2011). ${ }^{8}$ As

8 Colored adolescents have better job opportunities than African adolescents, due in part to the legacy of colored labor-market preferences under apartheid. Moreover, failing a grade is a better predictor of future failure in predominantly colored schools than in African schools, a result of differences in the quality of evaluation (Lam, Ardington, and Leibbrandt 2011). Both factors contribute to the higher dropout rate among coloreds, especially in response to failing a grade. 
TABLE 3 Percentage of respondents from CAPS Wave 1 enrolled in grades 9-11 in 2002 who are two or more or three or more years older than the normative age for grade, Cape Town, South Africa

\begin{tabular}{|c|c|c|c|c|c|}
\hline \multirow[b]{2}{*}{ Racial group } & \multirow[b]{2}{*}{$(\mathrm{N})$} & \multicolumn{2}{|c|}{$2+$ years older } & \multicolumn{2}{|c|}{$3+$ years older } \\
\hline & & $\begin{array}{c}\text { Girls/ } \\
\text { young } \\
\text { women }\end{array}$ & $\begin{array}{r}\text { Boys/ } \\
\text { young } \\
\text { men }\end{array}$ & $\begin{array}{c}\text { Girls/ } \\
\text { young } \\
\text { women }\end{array}$ & $\begin{array}{r}\text { Boys/ } \\
\text { young } \\
\text { men }\end{array}$ \\
\hline African & (797) & 43.2 & 56.6 & 22.1 & 32.8 \\
\hline Colored & $(680)$ & 7.7 & 13.6 & 1.7 & 4.2 \\
\hline White & (222) & 0.5 & 5.1 & 0.0 & 0.9 \\
\hline Total & $(1,699)$ & 17.9 & 24.1 & 8.0 & 11.7 \\
\hline
\end{tabular}

NOTE: Normative age is defined as 15 for ninth grade, 16 for tenth grade, and 17 for eleventh grade.

shown in Figures 2 and 3, white students are rarely two or more years older than the normative grade. Only 4 percent of white males and no white females in our sample were two or more years older than the normative age in grades 9-11. Looking at the final two columns in Table 3, 33 percent of African young men are three or more years older than the normative age for grade, a dramatic demonstration of the wide distribution in age-for-grade in this group. This compares with only 4 percent of colored males and 1 percent of white males.

Table 4 examines how key characteristics vary with age for African students in a single grade-ninth grade. We focus on Africans because they have by far the widest dispersion in age for grade. African ninth graders are fairly evenly distributed from age 14 to age 19-22. Younger students in a class are much more likely to be female than are older students. Whereas 62 percent of 14-year-olds in ninth grade are female, only 38 percent of those ages 19-22 are female. Table 4 also provides information regarding why such a wide age distribution in a given grade exists, showing both the age at starting school and the number of grades failed by 2002 (both estimated using the retrospective life history calendar). Clearly, many students are behind in school because they started school late. The mean age at starting school for 18-year-olds in ninth grade is 7.8, compared with 6.1 for the 15 -year-olds in ninth grade. ${ }^{9}$ Grade repetition also plays an important role, with 18-year-olds having failed 1.1 more grades than 15-year-olds.

TABLE 4 Characteristics (means) of African respondents in CAPS Wave 1 enrolled in ninth grade, by age, Cape Town, South Africa, 2002

\begin{tabular}{|c|c|c|c|c|c|c|c|}
\hline \multirow[b]{2}{*}{ Characteristic } & \multicolumn{7}{|c|}{ Age (in years) in 2002} \\
\hline & 14 & 15 & 16 & 17 & 18 & $19-22$ & Total \\
\hline$\overline{\text { Age }}$ & 14.6 & 15.5 & 16.4 & 17.5 & 18.4 & 20.3 & 17.1 \\
\hline Female & 0.62 & 0.71 & 0.63 & 0.51 & 0.49 & 0.38 & 0.56 \\
\hline Age at first grade & 5.2 & 6.1 & 6.6 & 7.2 & 7.8 & 8.6 & 6.9 \\
\hline Number of grades failed & 0.14 & 0.22 & 0.64 & 0.99 & 1.31 & 1.89 & 0.86 \\
\hline Had sex by 2002 & 0.03 & 0.28 & 0.38 & 0.47 & 0.69 & 0.87 & 0.46 \\
\hline Standardized LNE score & -0.12 & -0.36 & -0.63 & -0.63 & -0.78 & -1.10 & -0.62 \\
\hline Mother's highest grade & 9.72 & 8.43 & 8.32 & 7.64 & 8.02 & 6.11 & 7.99 \\
\hline Father's highest grade & 8.80 & 7.26 & 7.50 & 6.95 & 6.94 & 5.53 & 7.11 \\
\hline Log household income & 5.85 & 5.52 & 5.47 & 5.43 & 5.51 & 5.20 & 5.48 \\
\hline Mother coresident & 0.74 & 0.75 & 0.68 & 0.71 & 0.57 & 0.60 & 0.68 \\
\hline Father coresident & 0.48 & 0.31 & 0.39 & 0.40 & 0.48 & 0.40 & 0.40 \\
\hline Sample size & (33) & $(54)$ & $(80)$ & $(66)$ & $(44)$ & $(46)$ & (323) \\
\hline Percentage of total sample & 10.2 & 16.7 & 24.8 & 20.4 & 13.6 & 14.2 & 100.0 \\
\hline
\end{tabular}

LNE $=$ Literacy and numeracy evaluation.

9 According to the South African Schools Act of 1996, schooling is compulsory from age 7 to age 15 or the completion of ninth grade. 
Table 4 also illustrates how our three outcomes vary across age among ninth graders. We see a steep age gradient in sexual debut. Whereas only 3 percent of 14 -year-olds report having had sex, 69 percent of 18-year-olds and 87 percent of 19-22-year-olds (these two older groups account for 28 percent of African ninth graders) report having had sex by 2002. This gradient is central to the peer effects we are focusing on. For a 14-year-old girl in ninth grade, almost half of her classmates are already sexually active. The comparable number for colored ninth graders is 7 percent and for white ninth graders is 4 percent (not shown).

Individual and household characteristics vary with age (see Table 4). Younger ninth graders perform much better on the literacy and numeracy test than do older ninth-graders, with the mean for 14-year-olds being one standard deviation above the mean for 19-22-year-olds (not shown). Younger students have better-educated parents, presumably indicating that better-educated parents enroll their children in school earlier and help them make normal grade progression. Younger students are more likely to live with their mothers, although differences in household income between younger and older students are surprisingly small. All of these characteristics are likely to affect sexual initiation, so we include all of these variables in our regression analyses.

We also see from Table 4 that an African student who is fortunate enough to reach ninth grade by age 15 will have a substantial proportion of classmates who are older and sexually active. The older students will also tend to have poor academic performance. This lower achievement among the older students might have indirect peer effects that go beyond those related to sexual activity. The poorer school performance of older students may have a negative impact on the school performance of younger students, with spillover effects to sexual behavior.

\section{Analytical Strategy}

Our analysis focuses on 1,491 CAPS respondents who were aged 14-17 in 2002. To control carefully for age, we include a quadratic of age in months. We include an indicator for 2002 school enrollment, the highest grade attained in 2002, and the standardized score on the literacy and numeracy exam administered in 2002. Because variation exists in the time between Wave 1 and Wave 3 interviews, we include a control for the number of months between interviews. We also include a number of household characteristics. These include mother's and father's education (collected from the youth respondent even when the parent was not a coresident); log of per capita household income in 2002; dummies for colored and white; dummies to indicate whether the mother and father were coresidents with the young adult in 2002; and dummies to indicate that parental education is missing.

\section{RESULTS}

Table 5 presents descriptive statistics of key variables, broken down by gender and racial group. We see large racial differences in sexual activity by 2002. The proportion of African young people aged 14-17 reporting having had sex in CAPS Wave 1 is 30-34 percent, compared with 4-14 percent for colored and white young people. Our analysis of sexual debut is restricted to the sample that had not had sex by 2002. Within this group, 68 percent of African females and 61 percent of African males became sexually active by 2005. This compares with 37 percent of 
colored females, 30 percent of white females, 40 percent of colored males, and 36 percent of white males. The age difference of the first sexual partner among those who become sexually active ranges from 2.2 to 2.9 years for girls (which means the male partner is older), and from 0.12 to -0.5 years for males.

Several variables related to schooling are included in Table 5. School enrollment is well over 90 percent for all groups, but large racial differences are found in grade attainment. ${ }^{10}$ The largest differences are among boys. African boys aged 14-17 completed 6.8 grades on average, compared with 8.1 and 8.6 grades among colored and white boys, respectively. Our measure of exposure to older peers has a mean of 96 percent among African girls, 46 percent among colored girls, and 9 percent among white girls. Large racial differences are also observed in performance on the literacy and numeracy evaluation that was administered in Wave 1 . The English language test was taken by 99 percent of African respondents, 43 percent of colored respondents, and 64 percent of white respondents (not shown). ${ }^{11}$ We use the score as a measure of cumulative learning as of Wave 1, with performance on the test reflecting factors such as innate ability, home environment, and the quantity and quality of schooling to that point. African girls have a mean score that is 1.6 standard deviations below the mean score for white young women (not shown). As Lam, Ardington, and Leibbrandt (2011) indicate, the distribution of test scores for Africans and whites barely overlap. Enormous racial differences in income also exist. Household income per capita is almost ten times as high in the households of white 14-17-year-olds as the levels in the households of African 14-17-year-olds. Income in colored households is approximately two times the income in African households.

TABLE 5 Means of key variables, by sex and race, respondents in CAPS Wave 1-4 aged 14-17 in 2002, Cape Town, South Africa

\begin{tabular}{|c|c|c|c|c|c|c|}
\hline \multirow[b]{2}{*}{ Characteristic } & \multicolumn{3}{|c|}{ Girls } & \multicolumn{3}{|c|}{ Boys } \\
\hline & African & Colored & $\overline{\text { White }}$ & African & Colored & White \\
\hline Sample size & $(440)$ & $(492)$ & (117) & $(340)$ & $(443)$ & $(111)$ \\
\hline Had sex by 2002 & 0.03 & 0.08 & 0.05 & 0.34 & 0.14 & 0.04 \\
\hline Conditional sample size & $(265)$ & $(404)$ & $(90)$ & $(192)$ & $(347)$ & (90) \\
\hline Sexual debut 2002-05 & 0.68 & 0.37 & 0.30 & 0.61 & 0.40 & 0.36 \\
\hline Age difference of first sexual partner & 2.65 & 2.86 & 2.21 & 0.12 & 0.10 & -0.46 \\
\hline Enrolled in school in 2002 & 0.98 & 0.94 & 1.00 & 0.98 & 0.93 & 0.99 \\
\hline Grades completed in 2002 & 7.68 & 8.36 & 8.63 & 6.80 & 8.14 & 8.64 \\
\hline Grades completed in 2005 & 9.84 & 10.23 & 11.12 & 9.21 & 9.79 & 11.1 \\
\hline Exposure to peers $2+$ years older & 0.96 & 0.46 & 0.09 & 0.68 & 0.40 & 0.07 \\
\hline Literacy/numeracy score & -0.47 & 0.08 & 1.17 & -0.59 & 0.12 & 1.31 \\
\hline Household income per capita & 441 & 944 & 4,270 & 453 & 999 & 4,081 \\
\hline Log household income per capita & 5.59 & 6.49 & 8.10 & 5.59 & 6.53 & 8.09 \\
\hline Mother's highest grade & 8.49 & 8.68 & 12.65 & 8.63 & 8.98 & 12.83 \\
\hline Father's highest grade & 7.83 & 9.12 & 13.3 & 7.81 & 8.99 & 13.03 \\
\hline Mother coresident in 2002 & 0.72 & 0.81 & 0.94 & 0.79 & 0.83 & 0.97 \\
\hline Father coresident in 2002 & 0.42 & 0.55 & 0.77 & 0.44 & 0.61 & 0.80 \\
\hline Mother's grade missing & 0.09 & 0.09 & 0.04 & 0.08 & 0.10 & 0.00 \\
\hline Father's grade missing & 0.40 & 0.32 & 0.10 & 0.39 & 0.28 & 0.08 \\
\hline
\end{tabular}

NOTES: Variable for exposure to older students is cumulative from age 12. Household income per capita in rands per month in 2002.

10 As previously noted, schooling is compulsory until age 15 or the completion of ninth grade. Although some apparent violations of this are revealed in CAPS and other South African surveys, most young people stay in school beyond the legal minimum.

11 Although Africans took the test in a second language, English is the official language of instruction in African schools and is used for important tests such as the twelfth-grade matriculation exam. 


\section{Determinants of Sexual Debut}

Table 6 presents the results of our probit regression analyses that measure the impact of our peer exposure measure on sexual debut. The dependent variable is equal to 1 if the respondent became sexually active between 2002 and 2005, using the sample that had not had sex by 2002. We present marginal effects evaluated at the sample mean for all variables. Given sample size limitations, we pool the population groups but estimate separate regressions for girls and boys. Columns 1 and 4 leave out our peer exposure measure and the literacy/numeracy score. For girls, we estimate a positive but statistically insignificant effect of grade attainment on sexual debut. The estimated marginal effect of grade attainment implies that a girl with one additional year of schooling in 2002 (controlling for age) would be 3.6 percentage points more likely to become sexually active by 2005 . Evaluated at the mean probability of sexual debut for girls in all population groups combined (47 percent), this is an 8 percent increase in the probability of sexual debut. The effect for boys is similar-4.4 percentage points per year of schoolingand is statistically significant. Evaluated at the mean probability of sexual debut for boys in all population groups combined ( 46 percent), this is a 9.6 percent increase in the probability of sexual debut. We estimate a negative but statistically insignificant effect of being in school in 2002 on sexual debut among boys over the next three years. We find large negative marginal effects among boys on the colored and white dummies and similar effects among girls on the white dummy variable, indicating that the variables included in the regression do not explain the large racial differences in early sexual debut among these three groups.

Columns 2 and 5 add the literacy and numeracy evaluation (LNE) score to the regressions. The LNE score itself has a statistically significant negative effect on sexual debut for both girls and boys. A one standard deviation increase in the test score is associated with an 8.3 percent-

TABLE 6 Marginal effects from probit regressions for sexual debut between 2002 and 2005 among CAPS Wave 1-4 respondents aged 14-17 in 2002, Cape Town, South Africa

\begin{tabular}{|c|c|c|c|c|c|c|}
\hline \multirow[b]{2}{*}{ Variable } & \multicolumn{3}{|c|}{ Girls } & \multicolumn{3}{|c|}{ Boys } \\
\hline & (1) & (2) & (3) & (4) & (5) & (6) \\
\hline Enrolled in 2002 & -0.169 & -0.192 & -0.173 & $-0.304^{* *}$ & $-0.289^{\star *}$ & $-0.280^{* *}$ \\
\hline Grades completed in 2002 & 0.036 & $0.058^{*}$ & 0.015 & $0.044^{*}$ & $0.063^{* *}$ & 0.047 \\
\hline Exposure to peers $2+$ years older & - & - & $0.138^{*}$ & - & - & 0.071 \\
\hline Literacy/numeracy score & - & $-0.083^{\star *}$ & $-0.083^{* *}$ & - & -0.060 & -0.062 \\
\hline Colored & $-0.356^{\star *}$ & $-0.343^{\star \star}$ & $-0.252^{\star \star}$ & $-0.328^{\star *}$ & $-0.317^{\star \star}$ & $-0.281^{* *}$ \\
\hline White & $-0.282^{* *}$ & $-0.238^{* *}$ & -0.093 & -0.169 & -0.122 & -0.051 \\
\hline Log household income per capita & -0.018 & -0.008 & -0.010 & -0.040 & -0.031 & -0.032 \\
\hline Mother's highest grade & 0.008 & 0.012 & 0.012 & -0.019 & -0.017 & -0.017 \\
\hline Father's highest grade & $-0.028^{* *}$ & $-0.027^{\star *}$ & $-0.027^{\star *}$ & -0.015 & -0.015 & -0.015 \\
\hline Mother coresident in 2002 & -0.028 & -0.019 & -0.024 & -0.061 & -0.055 & -0.053 \\
\hline Father coresident in 2002 & -0.105 & -0.109 & $-0.113^{*}$ & -0.077 & -0.082 & -0.077 \\
\hline Age in months since age 14 & $0.017^{\star *}$ & $0.016^{* *}$ & $0.018^{* *}$ & $0.017^{\star}$ & $0.017^{\star}$ & $0.017^{\star}$ \\
\hline Age in months squared (x 1000) & -0.210 & -0.216 & -0.210 & -0.163 & -0.173 & -0.160 \\
\hline Number of months between waves & 0.003 & 0.003 & 0.004 & -0.020 & -0.020 & -0.020 \\
\hline Mother's grade missing & 0.038 & 0.083 & 0.070 & $-0.208^{\star}$ & -0.187 & -0.180 \\
\hline Father's grade missing & $-0.276^{* *}$ & $-0.275^{\star *}$ & $-0.274^{\star *}$ & -0.134 & -0.133 & -0.135 \\
\hline Observations & (808) & $(808)$ & (808) & (683) & (683) & $(683)$ \\
\hline
\end{tabular}

*Significant at $\mathrm{p}<0.05 ;{ }^{* *} \mathrm{p}<0.01$.

$-=$ Not applicable.

NOTES: Columns 1 and 4 leave out our peer exposure measure and the literacy/numeracy score. Columns 2 and 5 add the literacy/ numeracy score, and columns 3 and 6 introduce our measure of exposure since age 12 to peers who are at least two years older. 
age point reduction in the probability of sexual debut for girls. Also noteworthy is that including the LNE score causes the effect of highest grade completed to become even more positive for both young men and young women. This finding is consistent with our hypothesis that the grades-completed variable is partially reflecting the effect of exposure to older peers. When we do not include the LNE score in the regression, the highest-grade variable is indicative of two effects. The first effect is that students who are doing better in school and are more committed to school may be less likely to become sexually active. The second effect is the influence of older peers, which tends to encourage sexual initiation. When we include the LNE score, it incorporates some of the first effect, leaving the highest grade variable to indicate more of the second effect.

Columns 3 and 6 introduce our measure of exposure since age 12 to peers at least two years older. This variable is estimated to have a statistically significant positive effect on sexual debut among girls. The marginal effect of 0.138 implies that an increase in cumulative exposure by 1.0 would increase the probability of sexual debut by 13.8 percentage points. An increase in cumulative exposure of 1.0 could result from an increase in the proportion of classmates who were at least two years older of 25 percentage points in each of four years since age 12, an increase of 50 percentage points in each of two years, or any other combination that adds up to 1.0. The standard deviation of this variable for Africans is 0.7 , so an increase of 1.0 is an empirically plausible example. The estimated effect of the peer exposure variable is only about half as great for males and is not statistically significant. This is similar to the results of a study finding significant peer effects for girls but not for boys in the United States (Argys and Rees 2008).

Another important result shown in Table 6 is that including the peer exposure variable causes the estimated effect of grades completed to become smaller for boys and to become much smaller for girls. For girls the estimated marginal effect of grades completed falls from 0.058 to 0.015 and loses statistical significance. For boys the marginal effect falls from 0.063 to 0.047 , becoming only marginally significant $(\mathrm{p}=0.09)$. This supports our hypothesis that the apparent positive effect of grades completed on sexual debut is the result of an effect of exposure to older peers. Also striking is that the coefficient for colored drops by about 27 percent among girls when the peer exposure variable is added to the regression. The coefficient for white drops by more than 60 percent among girls and becomes statistically insignificant. This suggests that the much greater exposure of African girls in secondary school to peers who are at least two years older plays a substantial role in explaining the earlier sexual debut of African girls, compared with colored and white girls.

\section{Peer Effects and Age of First Sexual Partner}

The influence of older classmates on the timing of sexual debut could work through a number of channels. The simplest version of the "contagion effect" hypothesis is that interacting with peers who are sexually active, whether of the same or opposite sex, may make an individual more likely to decide to experiment with sexual activity. Another possibility is that individuals become sexually active with their classmates (or friends of their classmates). This might be especially pertinent to the girls in our sample, whose first sexual partners are two to three 
TABLE 7 Coefficients from ordinary least square regressions reflecting difference in age (in years) between CAPS respondents aged 14-17 in 2002 and their first sexual partner, Cape Town, South Africa

\begin{tabular}{lrr}
\hline Variable & Girls & Boys \\
\hline Enrolled in 2002 & 0.859 & -0.137 \\
Grades completed in 2002 & -0.475 & -0.109 \\
Exposure to peers 2+ years older & $0.870^{\mathrm{a}}$ & 0.057 \\
Literacy/numeracy score & $0.588^{*}$ & 0.214 \\
Colored & $1.226^{*}$ & 0.076 \\
White & 1.749 & -0.482 \\
Log household income per capita & $-0.488^{\star}$ & 0.002 \\
Mother's highest grade & -0.019 & 0.027 \\
Father's highest grade & -0.047 & -0.022 \\
Mother coresident in 2002 & -0.141 & -0.233 \\
Father coresident in 2002 & 0.136 & 0.215 \\
Age in months since age 14 & 0.006 & 0.001 \\
Age in months squared (x 1000) & 0.308 & -0.122 \\
Number of months between waves & -0.007 & 0.048 \\
Mother's grade missing & -0.591 & -0.171 \\
Father's grade missing & 0.223 & 0.464 \\
Observations & $(348)$ & $(280)$ \\
\hline
\end{tabular}

${ }^{\star}$ Significant at $\mathrm{p}<0.05 . \quad{ }^{\mathrm{a}} \mathrm{p}=0.06$.

NOTE: Sample is restricted to respondents who had not had sex in Wave 1.

years older on average (see Table 5). We might expect, then, that exposure to older classmates would have an effect on the age of the first sexual partner in addition to having an effect on sexual debut.

CAPS collected information about a number of characteristics of the first sexual partner, including age. Table 7 presents regressions in which the dependent variable is the age difference between the respondent and her/his first sexual partner, using only the sample that became sexually active between 2002 and 2005. Our regression analysis for girls reveals a positive effect of our peer exposure variable on the age difference between female respondents and their first sexual partner. The coefficient is just short of being statistically significant $(p=0.06)$. An increase in the cumulative peer exposure of 1.0 is associated with an increase in the age difference of the first sexual partner of 0.87 years. This provides additional evidence that exposure to older peers is affecting sexual behavior. Although we cannot tell whether the first sexual partner is a classmate (or a friend of a classmate), the results in Tables 6 and 7 suggest that girls with older classmates have both earlier sexual debut and older first sexual partners. Among boys, the estimated effect of exposure to older peers on the age of the first sexual partner is not statistically significant.

\section{Impact of Passing a Grade on Sexual Debut}

One somewhat extreme implication of our hypothesis that the presence of older classmates increases the probability of sexual debut is that students who pass a given grade, especially in high school, are more likely to become sexually active than students of the same age who fail the grade. For this to occur, the impact of older classmates would have to be strong enough to overcome what is presumably a tendency for students who pass a grade to be students with a stronger commitment to school and an associated lower probability of becoming sexually 
active. We examine this directly by looking at the impact of passing a grade on subsequent sexual debut.

An advantage of using grade advancement as an independent variable is that it is a more direct measure than our cumulative peer exposure measure. The variable has larger withinrace variation, because the cumulative exposure measure is based on average age-for-grade distributions by race. The disadvantage of the grade advancement measure is that it is subject to even greater endogeneity bias than the cumulative exposure measure, because students who pass a given grade will be positively selected on many characteristics that are likely to deter sexual debut. The biases created by the endogeneity of grade advancement will therefore tend to work against our finding a positive relationship between grade advancement and sexual debut.

Table 8 presents the coefficients from regressions on sexual debut that incorporate grade advancement as an independent variable. We estimate separate regressions by race and sex, taking advantage of the fact that substantial within-race variation in grade advancement exists. The dependent variable equals 1 if a respondent was in school in 2002 and was in school in 2003 in a grade at least one grade higher than 2002. The grade advancement variable equals 0 if the respondent was in school in 2002 and was in school in 2003 in a grade at or below the 2002 grade. The 2002 pass rate was 88 percent for African girls and boys aged 14-17, 92 percent for colored girls this age, 90 percent for colored boys, and 99 percent for white girls and boys. Because of the almost 100 percent pass rate for whites, we exclude them from the analysis in Table 8.

To maximize sample size, the regressions in Table 8 use all respondents in grades 9-11 in 2003 regardless of age. ${ }^{12}$ The dependent variable is the same as in Table 6 -it equals 1 if the respondent becomes sexually active between 2002 and 2005 and equals 0 if the respondent does not begin sexual activity by 2005. The regressions for African and for colored girls/young women indicate that those who pass to the next grade between 2002 and 2003 have a greater probability of sexual debut than do those who fail. African girls/young women who advance one grade are 21 percentage points more likely to become sexually active by 2005 than are African girls/young women who remain in the same grade in 2003. The difference for colored girls/young women is 14 percentage points. The estimates for young men are not statistically significant. For African girls/young women, the impact of the peer exposure variable remains positive and statistically significant even after having introduced into the model the impact of grade advancement from 2002 to $2003 .^{13}$

Passing the grade in 2002 is obviously not a randomly assigned characteristic. Young women who pass are likely to differ in many respects from young women who fail, even after controlling for the individual and household characteristics included in the regressions in Table 8. Most of these differences, such as unmeasured attachment to school, school quality, and home and neighborhood environmental influences, would lead us to expect that young women who fail the grade would be more likely, not less likely, to become sexually active. One variable working in the direction of the effect we see is that young women who pass the grade

12 We conducted analyses restricted to those younger than age 17 (not shown), and the results were similar.

13 Note that the peer exposure variable is only measured through 2002 and is, therefore, unaffected by whether grade advancement from 2002 to 2003 occurred. 
TABLE 8 Marginal effects from regressions for sexual debut between 2002 and 2005 among CAPS Wave 1-4 respondents enrolled in grades 9-11 in 2002, by grade advancement in 2002-03 and the previous independent variables, according to sex and race, Cape Town, South Africa

\begin{tabular}{|c|c|c|c|c|}
\hline \multirow[b]{2}{*}{ Characteristic } & \multicolumn{2}{|c|}{ Girls } & \multicolumn{2}{|c|}{ Boys } \\
\hline & African & Colored & African & Colored \\
\hline Advanced grade from 2002 to $2003^{\mathrm{a}}$ & $0.207^{*}$ & $0.137^{*}$ & -0.105 & -0.007 \\
\hline Exposure to peers $2+$ years older & $0.139^{*}$ & 0.083 & 0.135 & 0.163 \\
\hline Literacy/numeracy score & $-0.113^{* *}$ & -0.085 & $-0.109^{*}$ & 0.007 \\
\hline Log household income per capita & -0.045 & -0.067 & -0.003 & -0.033 \\
\hline Mother's highest grade & 0.018 & 0.023 & $0.027^{*}$ & $-0.046^{*}$ \\
\hline Father's highest grade & -0.001 & $-0.036^{*}$ & -0.003 & -0.004 \\
\hline Mother coresident in 2002 & -0.096 & 0.0601 & $-0.154^{*}$ & $-0.504^{\star \star}$ \\
\hline Father coresident in 2002 & -0.041 & 0.018 & -0.101 & 0.135 \\
\hline Grade in 2002 & -0.007 & 0.162 & 0.043 & $-0.167^{\star}$ \\
\hline Age in months since age 14 & -0.008 & -0.009 & 0.009 & 0.001 \\
\hline Age in months squared $(x$ 1000) & $0.205^{*}$ & 0.199 & -0.075 & 0.307 \\
\hline Number of months between waves & 0.007 & -0.002 & 0.008 & $-0.079^{\star *}$ \\
\hline Mother's grade missing & $0.144^{*}$ & $0.385^{*}$ & $0.154^{* *}$ & $-0.421^{\star *}$ \\
\hline Father's grade missing & 0.059 & -0.189 & -0.296 & 0.196 \\
\hline Observations & $(179)$ & $(264)$ & $(97)$ & $(181)$ \\
\hline
\end{tabular}

Significant at ${ }^{*} \mathrm{p}<0.05 ;{ }^{* *} \mathrm{p}<0.01$.

NOTE: Table shows marginal effects from probit regression, evaluated at sample means.

a Advanced grade equals 1 if respondent was enrolled in 2003 at a grade higher than their 2002 grade. Advanced grade equals 0 if respondent was enrolled in 2003 in a grade at or below their 2002 grade.

will be exposed to older classmates in the following year. The findings in Table 8 suggest that this peer exposure effect is strong enough to result in a positive relationship between passing a grade and subsequent sexual debut.

\section{LIMITATIONS}

Our data and our constructed variables have a number of limitations. One concern with our sexual behavior variables are that they are self-reported. The CAPS sexual behavior questions are similar to those asked in surveys such as the Demographic Health Survey. As Nnko and colleagues (2004) and Gersovitz (2005) have shown, sexual behavior may not be reported accurately, even when interviews are conducted in a private setting by well-trained interviewers. Our biggest concern in this regard would be that exposure to older classmates leads individuals to report having had sex when they had not. Although we cannot verify self-reports of sexual behavior, we think it unlikely that inaccurate reports are responsible for our results.

Our measure of cumulative exposure to older classmates, which we consider one of the innovations of our analysis, has a number of limitations. One limitation is that our measure is only an estimate of students who were in the same grade as the respondent in a given year, which ignores the potential effect of interacting with older students from other grades or with those who are not in school. Another limitation of our measure is that it does not distinguish between older male classmates and older female classmates. Although we have constructed separate measures for exposure to older males versus exposure to older females, the male and female measures are so highly correlated that estimating separate effects of the two measures is not possible. Given our measure, students with high exposure to older boys/young men will also have had high exposure to older girls/young women. Although we would be better able 
to understand the mechanisms if we could separate the effect of older males from the effect of older females, practical limitations prevented our doing so. ${ }^{14}$

Because variation in our peer exposure measure depends on variation in the age of starting school, as well as on grade repetition and interruptions in schooling, correlations are likely with characteristics such as the student's (and parents') commitment to school, the student's academic ability, and neighborhood characteristics. Our controls for baseline variables such as grade attainment, literacy/numeracy scores, and household income should remove much of this correlation, but the exposure variable may nevertheless be correlated with unobserved determinants of sexual debut. ${ }^{15}$ Most of these effects would lead us to expect that students who are further ahead in school (and thus have high values of the peer exposure variable) would be less likely to become sexually active. The bias in our estimates, then, should work against finding a positive effect of exposure to older peers on sexual debut. The fact that we do estimate a positive effect gives us confidence that the effect we are measuring is a real effect of peer exposure.

Another concern is that our variable for exposure to older classmates is highly correlated with grade attainment. ${ }^{16}$ When we include both variables, they compete with one another to explain sexual debut. This creates a risk that neither variable would be estimated precisely enough for statistical significance given the correlation. The fact that the coefficient on our peer exposure variable is statistically significant suggests that it is a better predictor of sexual debut than is the grade attainment variable. The high correlation between grade attainment and peer exposure does not inevitably cause the coefficient on grade attainment to decline when we add peer exposure in Regression 3 of Table 6. In fact, the decline in the coefficient for grade attainment is much smaller in the regression for boys, even though grade attainment and peer exposure are just as correlated for boys as they are for girls.

Another limitation of our analysis is that we are not able to identify the precise mechanisms driving the effect of exposure to older classmates. If girls are having sex with older male classmates by virtue of their proximity, this is not really a contagion effect in the usual sense. Alternatively, the results may mean that girls are being influenced to adopt the behavior of their older female classmates, which is more of a traditional contagion effect.

\section{SUMMARY AND CONCLUSIONS}

South Africa's combination of early sexual debut, high rates of school enrollment through late teenage years, and high rates of grade repetition create an environment in which moving through school faster than one's age-mates equates to being exposed to significant numbers of older classmates who are already sexually active. Previous research has provided sugges-

14 Only a small minority of students in South Africa attend single-sex schools. We attempted to identify the respondents attending single-sex schools, but the number we were able to identify was small. Additionally, the single-sex schools we were able to identify were mainly elite private schools catering to high-income whites, and thus not broadly representative.

15 In regressions not shown, we included measures of school quality (pupil-teacher ratios and the percentage of teachers hired by the parent governing body, taken from matching the 2000 School Register of Needs to school names reported in CAPS) and neighborhood unemployment among young people (based on 2001 census data at the "small area" level). The results were almost identical, with a slightly greater and statistically more significant estimate of the impact of the peer exposure measure.

16 Grade attainment is also correlated with the literacy/numeracy variable. This correlation is only about 0.4 , however, even for a single age/race/gender group. As a result, sufficient variation exists to estimate separate effects of the two variables in Regression 2 of Table 6. One reason for the modest correlation is the poor system of evaluation in many schools, leading to a situation in which actual learning is a weak predictor of grade advancement (Lam, Ardington, and Leibbrandt 2011). 
tive evidence of such peer effects, identifying a surprising positive relationship between grade attainment and subsequent sexual debut, controlling for age. This study attempts to provide clearer evidence of the existence of peer contagion effects, taking advantage of several features of the Cape Area Panel Study. We document two important features of schooling and sexual debut that create the potential for contagion effects. First, we show that a steep age-gradient in sexual debut for young men and young women exists in all three of the racial groups we study-African, colored, and white. Second, we show that high rates of grade repetition and secondary-school enrollment that continues even beyond age 20 lead to high variance in the age-for-grade distribution, especially for Africans. Using the retrospective schooling histories collected in the Cape Area Panel Study, we generate race-specific age-for-grade distributions for all grades and use these to estimate the history of exposure beginning at age 12 to classmates who are at least two years older.

Our probit regressions indicate that our measure of cumulative exposure to older peers in 2002 has a positive and statistically significant impact on sexual debut between 2002 and 2005, controlling for baseline age, grade attainment, literacy and numeracy competence, and a number of household background variables. Being exposed for two years to 50 percent more classmates who are at least two years older increases the probability by 14 percentage points that a girl becomes sexually active between 2002 and 2005. Additionally, inclusion of our peer exposure variable causes the estimated effect of baseline grade completion on age at sexual debut in the subsequent three years to drop from a statistically significant positive effect to a much smaller and statistically insignificant effect. The exposure variable also causes the estimated marginal effect of being colored rather than African to fall by 25 percent and the estimated effect of being white to drop by more than 60 percent and become statistically insignificant. This is provocative evidence suggesting that early sexual debut among urban South Africa's African girls may partly result from the much greater degree of exposure to older classmates that students encounter in African schools. As further evidence of this effect, we show that young women in grades 9-11 who passed their grade in 2002 were significantly more likely to become sexually active than young women who did not pass their grade.

Our measure of exposure to older peers is also estimated to have a modest positive effect on the age of girls' first sexual partner (marginally significant at $\mathrm{p}=0.06$ ). This is consistent with the argument that exposure to older peers is a factor in encouraging earlier sexual debut.

Our findings provide an important caveat to the view that additional schooling delays sexual debut. Although girls attending school are less likely to become sexually active than are girls who are not in school, female students who are ahead of their cohorts in advancing through school face the potentially negative consequences of interacting with classmates who may be four or five years older. This may be an important factor for policymakers to take into account when evaluating the high rates of grade repetition in disadvantaged South African schools.

\section{REFERENCES}

Anderson, Kermyt, Anne Case, and David Lam. 2001. "Causes and consequences of schooling outcomes in South Africa: Evidence from survey data," Social Dynamics 27(1): 1-23.

Argys, Laura M. and Daniel I. Rees. 2008. "Searching for peer group effects: A test of the Contagion Hypothesis," Review of Economics and Statistics 90(3): 442-458. 
Biddlecom, Ann, Richard Gregory, Cynthia B. Lloyd, and Barbara S. Mensch. 2008. “Associations between premarital sex and leaving school in four sub-Saharan African countries,” Studies in Family Planning 39(4): 337-350.

Clark, Shelley and Rohini Mathur. 2012. “Dating, sex and schooling in urban Kenya," Studies in Family Planning 43(3): $161-174$.

Darabi, Leila, Akinrinola Bankole, Kalundi Serumaga, Stella Neema, Richard Kibombo, Humera Ahmed, and Paul Banoba. 2008. "Protecting the next generation in Uganda: New evidence on adolescent sexual and reproductive health needs.” New York: Guttmacher Institute.

Dinkelman, Taryn, David Lam, and Murray Leibbrandt. 2007. "Household and community income, economic shocks and risky sexual behavior of young adults: Evidence from the Cape Area Panel Study 2002 and 2005," AIDS 21(Suppl. 7): S49-S56.

- 2008. "Linking poverty and income shocks to risky sexual behaviorur: Evidence from a panel study of young adults in Cape Town," South African Journal of Economics 76(Suppl. 1): S52-S74.

Eisenberg, Daniel. 2004. “Peer effects for adolescent substance use: Do they really exist?” Working Paper. Berkeley, CA: School of Public Health, University of California.

Fitzgerald, John, Peter Gottschalk, and Robert Moffitt. 1998. “The impact of attrition in the panel study of income dynamics on intergenerational analysis," Journal of Human Resources 33(2): 300-344.

Gaviria, Alejandro and Steven Raphael. 2001. "School-based peer effects and juvenile behavior," Review of Economics and Statistics 83(2): 257-268.

Gersovitz, Mark. 2005. "The HIV epidemic in four African countries seen through the Demographic and Health Surveys," Journal of African Economies 14(2): 191-246.

Lam, David, Cally Ardington, Nicola Branson, et al. 2008. "The Cape Area Panel Study: Overview and technical documentation of Waves 1-2-3-4 (2002-2006).” Working Paper. Rondebosch, South Africa: University of Cape Town.

Lam, David, Cally Ardington, and Murray Leibbrandt. 2011. "Schooling as a lottery: Racial differences in school advancement in Urban South Africa," Journal of Development Economics 95(2): 121-136.

Lloyd, Cynthia. 2005. Growing Up Global: The Changing Transitions to Adulthood in Developing Countries. Washington, DC: National Academies Press.

2007. "The role of schools in promoting sexual and reproductive health among adolescents in developing countries.” Poverty, Gender, and Youth Working Paper No. 6. New York: Population Council.

Marteleto, Letícia, David Lam, and Vimal Ranchhod. 2008. "Sexual behavior, pregnancy, and schooling among young people in urban South Africa," Studies in Family Planning 39(4): 351-368.

Nnko, Soori, J. Ties Boerma, Mark Urassa, Gabriel Mwaluko, and Basia Zaba. 2004. “Secretive females or swaggering males?: An assessment of the quality of sexual partnership reporting in rural Tanzania," Social Science \& Medicine 59(2): 299-310.

Sacerdote, Bruce. 2001. "Peer effects with random assignment: Results for Dartmouth roommates," Quarterly Journal of Economics 116(2): 681-704.

Sieving, Renee E., Marla E. Eisenberg, Sandra Pettingell, and Carol Skay. 2006. "Friends' influence on adolescents' first sexual intercourse," Perspectives on Sexual and Reproductive Health 38(1): 13-19.

\section{ACKNOWLEDGMENTS}

We are thankful for the support for this research provided by the US National Institute of Child Health and Human Development, the Fogarty International Center of the US National Institutes of Health, and the Hewlett Foundation. We are also grateful for the excellent research assistance provided by Kendra Goostrey. 